\title{
Chronic Alcohol Consumption Affects Serum Enzymes Levels in the HIV-Infected Patients on Stavudine (d4T)/Lamivudine (3TC)/Nevirapine (NVP) Treatment Regimen
}

\author{
Godfrey S. Bbosa ${ }^{1 *}$, David B. Kyegombe ${ }^{2}$, William W. Anokbonggo ${ }^{1}$, Aloysius Lubega ${ }^{1}$, \\ Apollo Mugisha $^{3}$, Jasper Ogwal-Okeng ${ }^{1}$ \\ ${ }^{1}$ Department of Pharmacology and Therapeutics, Makerere University College of Health Sciences, Kampala, Uganda; ${ }^{2}$ Department \\ of Pharmacology \& Toxicology, Kampala International University College of Health Sciences, Ishaka Campus, Kampala, Uganda; \\ ${ }^{3}$ Clinical Chemistry Laboratory, Mulago Complex National Referral Hospital, Kampala, Uganda. \\ Email: "godfossa@yahoo.com
}

Received December $17^{\text {th }}$, 2013; revised January $17^{\text {th }}$, 2014; accepted January $28^{\text {th }}, 2014$

Copyright (C) 2014 Godfrey S. Bbosa et al. This is an open access article distributed under the Creative Commons Attribution License, which permits unrestricted use, distribution, and reproduction in any medium, provided the original work is properly cited. In accordance of the Creative Commons Attribution License all Copyrights (C) 2014 are reserved for SCIRP and the owner of the intellectual property Godfrey S. Bbosa et al. All Copyright (C) 2014 are guarded by law and by SCIRP as a guardian.

\section{ABSTRACT}

Chronic alcohol use is a common problem globally among the HIV-infected patients on ARV treatment regimens, leading to severe liver damage and increase in serum enzymes. The study determined effect of chronic alcohol intake on serum enzymes (alanine aminotransferase (ALT), aspartate aminotransferase (AST) and $\gamma$-glutamyl transferase (GGT)) in HIV-infected patients on d4T/3TC/NVP treatment regimen in Uganda using the WHO alcohol use disorders' identification test (AUDIT) tool and chronic alcohol use biomarkers (ALT, AST, GGT, AST/ALT $\geq 2.0$ and mean corpuscular volume (MCV)). A case control study using repeated measure design with serial measurements model was used. Alcohol use biomarkers were used to standardize the gender differences in alcohol use. A total of 41 patients (21 alcohol group and 20 control group) were followed up for 9 months with blood sampling done at 3 month intervals. The serum enzymes' levels were determined by using the Cobas Intergra 400 Plus analyzer system. The mean GGT levels were higher in chronic alcohol use group as compared to control group in both groups. The levels were above reference ranges during 6 month and three times higher during 9-month follow-up period for both chronic alcohol use self reporting WHO AUDIT tool and biomarkers' groups. Generally, the mean AST, ALT and AST/ALT levels were slightly higher in alcohol use group as compared to control group and were slightly higher in both groups as compared to reference ranges during the 9 month follow-up period. Chronic alcohol consumption by HIV-infected patients on d4T/3TC/NVP drug regimen increased GGT and AST/ALT serum enzyme levels and hence was used as chronic alcohol use biomarkers.

\section{KEYWORDS}

\section{Chronic Ethanol Use; Serum Enzymes; HIV-Infected Patients; Antiretroviral (ARVs) Drugs}

\section{Introduction}

Alcohol, mainly ethanol, is by far the most abused drug for centuries globally [1-3]. The types of alcohol consumed in alcoholic beverages include wine, spirits, liquors, beers and as traditional brew especially in develop-

"Corresponding author. ing countries. The World Health Organization (WHO) estimates that there are about 2 billion people in both developing and developed countries globally who consume the different forms of alcoholic beverages [4-6] (WHO, 2011). And it is currently reported that females are the drivers of the increased cases of alcohol consumption in both developed and developing countries [7]. 
Also alcohol consumption is the leading risk factor for disease burden like HIV infection especially in developing countries and the third largest risk factor in developed countries accounting for $4 \%$ of the burden of the diseases $[4,8,9]$. Among the chronic alcohol users are the HIV-infected patients. HIV/AIDS is still a global problem and the HIV prevalence varies in the different regions of the world with the sub Saharan Africa still experiencing the burden (Figure 1) [10]. And in Uganda, currently the HIV prevalence stands at $7.3 \%$ and there is regional variation in urban and rural areas of the country (Figure 1) [11].

Many of the HIV-infected patients are currently on various antiretroviral (ARVs) drug regimes. However, some of the patients on ARVs are reported to consume alcohol chronically despite of the rigorous counseling prior to initiation of treatment to change their lifestyles or behaviors including alcohol use. Chronic alcohol use by the patients

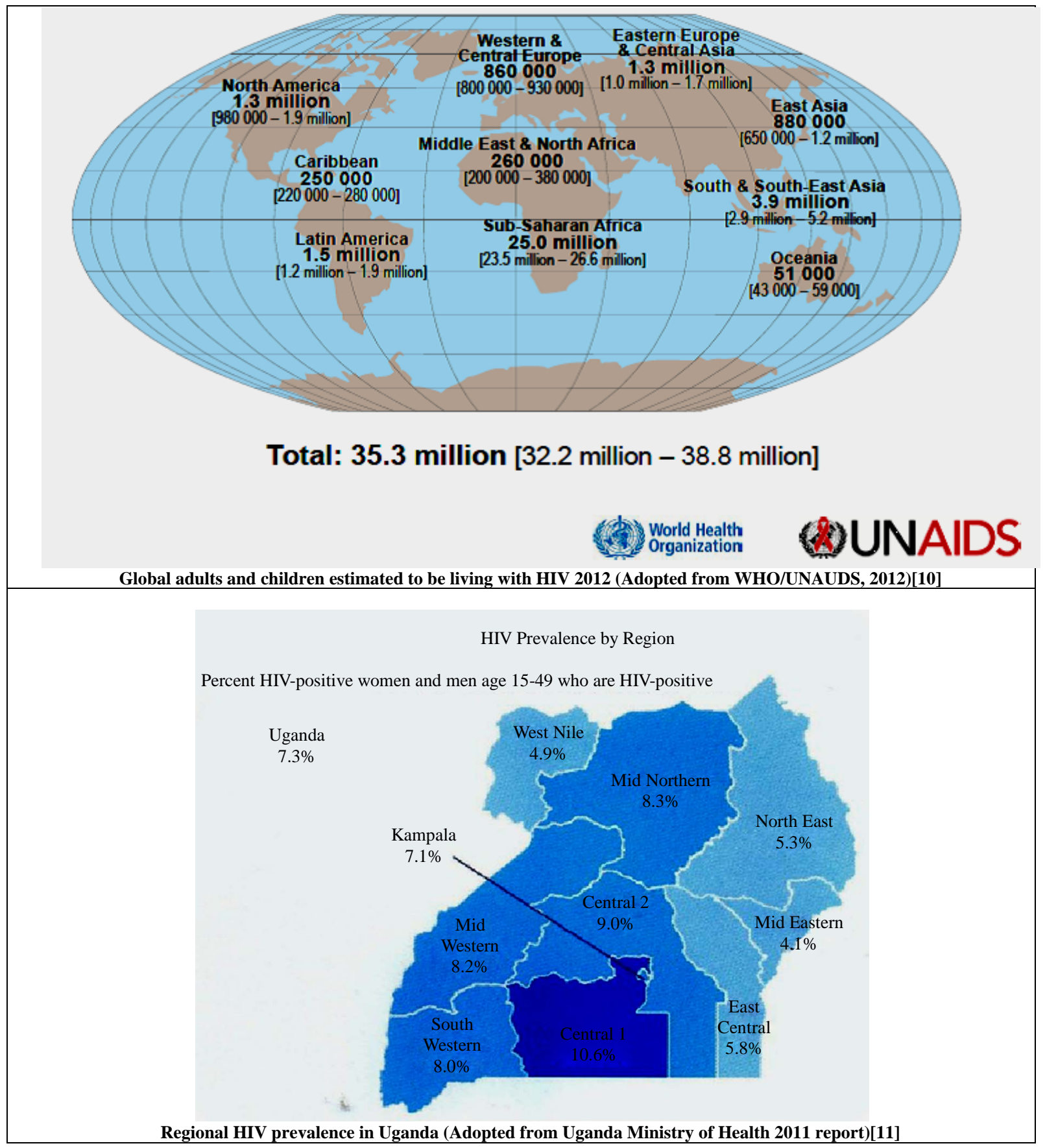

Figure 1. Estimated current global and Uganda regional HIV prevalence. 
leads to ethanol-drug-HIV virus interactions that can damage the various body organs and tissues especially the liver, thus affecting the serum enzyme levels.

In Uganda, various types of alcoholic beverages are consumed, including the home-made brews that are consumed in the countryside (Table 1 ).

It is a serious problem in the country and is ranked as a top most country in alcohol consumption among the 189 WHO member countries and in the African region [1217]. However, among the people who consume alcohol are the HIV-infected patients, some of whom are on antiretroviral drugs like the $\mathrm{d} 4 \mathrm{~T} / 3 \mathrm{TC} / \mathrm{NVP}$ drug regimen $[18,19]$. The liver is the main site of ethanol metabolism especially in the females though metabolism can also occur in other tissues such as the gastrointestinal tract (GIT) mainly in the males and other body tissues [20-24].

In the body, especially in the liver and the gastrointestinal tract (GIT), ethanol is broken down by a number of metabolizing enzyme systems by both the oxidative and non-oxidative pathways to generate a number of potentially harmful byproducts that cause deleterious effects on the body tissues and organs [21,24,25]. Ethanol is metabolized by various enzymes including the alcohol dehydrogenase $(\mathrm{ADH})$ enzyme isoforms and aldehyde dehydrogenase (ALDH), cytochrome P450 enzyme system and catalase [21,24-26] (Figure 2).
There are various ADH and ALDH enzyme isoforms that play a significant role in ethanol metabolism. Class I $\mathrm{ADH}$ and ALDH2 play a central role in alcohol metabolism [21,24-26]. Variations in the genes encoding ADH and ALDH produce alcohol- and acetaldehyde-metabolizing enzymes that vary in activity. This genetic variability influences a person's susceptibility to developing alcoholism and alcohol-related tissue damage. Several isozymes of ALDH have been identified, but only the cytosolic ALDH1 and the mitochondrial ALDH2 metabolize acetaldehyde. ALDH2 plays an important role in determining peak blood acetaldehyde levels and voluntary ethanol consumption and also influences vulnerability to alcohol dependence [21,24-26] (Table 2).

The cytochrome P450 isozymes include CYP2E1, 1A2 and 3A4. Most especially, the CYP2E1 is induced by chronic alcohol consumption and plays an important role in metabolizing ethanol to acetaldehyde at elevated ethanol concentrations. The CYP2E1-dependent ethanol oxidation also occurs in other tissues like the brain where ADH activity is low [21,24-26]. It also produces reactive oxygen species (ROS), including hydroxyethyl, superoxide anion and hydroxyl radicals, which increase the risk of tissue damage especially to the liver hepatocytes. Alcohol also enhances the activity of the central enzyme of the microsomal ethanol oxidizing system (MEOS), cytochrome P450 2E1, which exacerbates some

Table 1. The commonest traditional alcohol (local brew) in Uganda.

\begin{tabular}{|c|c|}
\hline Traditional brew (Local brew) in Uganda & Sources \\
\hline \multicolumn{2}{|l|}{ Fermented alcohol beverages } \\
\hline Ajon or Malwa or Kongo or Abasohi & Millet beer \\
\hline Tonto or bwakata or mwenge bigere & Banana wine with sorghum \\
\hline Mbege & Banana and millet ferment \\
\hline Kweete & Maize beer from maize and malted millet flour \\
\hline Busheera & Millet wine \\
\hline Omuramba & Sorghum ferment \\
\hline Munanasi & Pineapple wine \\
\hline Kalire & Banana fermented without sorghum \\
\hline \multicolumn{2}{|l|}{ Spirits } \\
\hline Waragi or enguli, kasese or mandule or arege & High alcoholic content ( $40 \% \mathrm{v} / \mathrm{v}$ and above) \\
\hline Lira-lira or lujutu & Distilled from cassava \\
\hline Ting & Residue of cassava liquor with low alcoholic content \\
\hline \multicolumn{2}{|l|}{ Mixtures (liquors or spirits) } \\
\hline Kaliga or kikulu & Cocktail of banana wine and spirits \\
\hline Ajabajaba & Freshly heated maize flour mixed with spirits \\
\hline
\end{tabular}




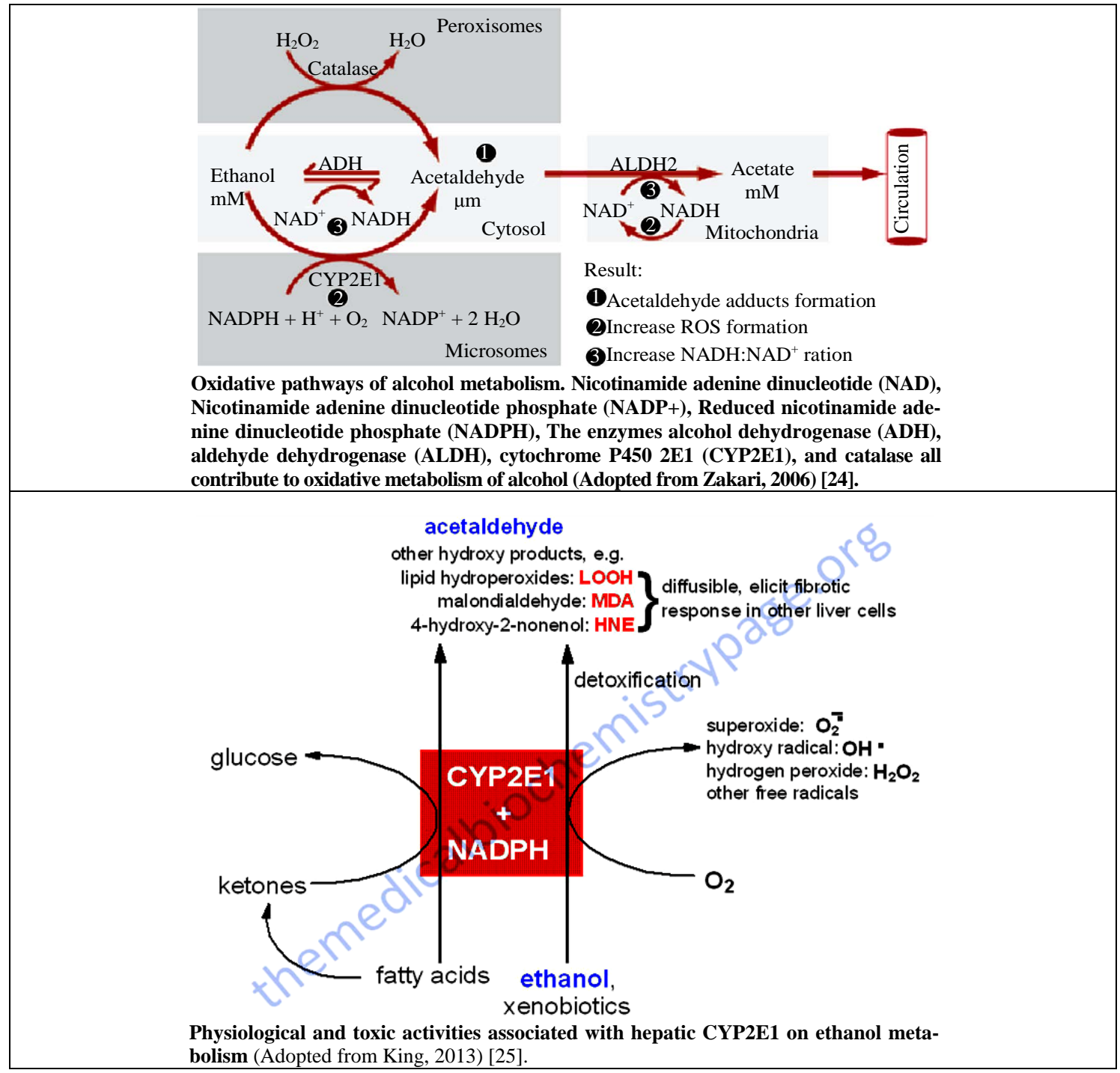

Figure 2. Metabolism of ethanol and generation of reactive oxygen species (ROS) in the body.

Table 2. Mammalian Alcohol Dehydrogenases (ADH) and aldehyde dehydrogenases (ALDH) involved in alcohol metabolism [21,24-26].

\begin{tabular}{|c|c|c|c|c|c|}
\hline Gene Name & Gene Class & Protein Name & $K_{M}(m M)$ for Ethanol & Primary Tissue & Metabolic function \\
\hline ADH1A & I & $\alpha$ & 4.0 & liver & \multirow{6}{*}{ Metabolize $70 \%$ of ethanol in the liver } \\
\hline ADH1B $* 1$ & I & $\beta_{1}$ & 0.05 & liver, lung & \\
\hline ADH1B*2 & I & $\beta_{2}$ & 0.9 & & \\
\hline ADH1B*3 & I & $\beta_{3}$ & 40 & & \\
\hline ADH1C*1 & I & $\gamma_{1}$ & 1.0 & liver, stomach & \\
\hline ADH1C*2 & I & $\gamma_{2}$ & 0.6 & & \\
\hline $\begin{array}{l}\text { ADH5 (also identified } \\
\text { as ADHX) }\end{array}$ & III & $\chi$ & $>1,000$ & widely expressed & $\begin{array}{l}\text { Has a very low affinity for ethanol and } \\
\text { used in methanol metabolism }\end{array}$ \\
\hline ADH6 & $\mathrm{V}$ & ADH6 & unknown & stomach & $\begin{array}{l}\text { Found in both fetal and adult liver; } \\
\text { unknown function }\end{array}$ \\
\hline ADH7 & IV & $\mu$ or $\sigma$ & 30 & liver, stomach & Involved in both ethanol and retinol oxidation \\
\hline \multicolumn{4}{|c|}{ ALDH1 } & $\begin{array}{l}\text { Cell cytosol, brain } \\
\text { and other tissues }\end{array}$ & $\begin{array}{l}\text { Eliminates acetaldehyde and keep its levels low } \\
\text { and involved in the synthesis of retinoic acid }\end{array}$ \\
\hline
\end{tabular}


of the toxic effects of acetaldehyde and generates a harmful condition called oxidative stress in the cells that is characterized by excess levels of reactive oxygen species (ROS). Acetaldehyde, a reactive metabolite of ethanol, binds to proteins such as enzymes, microsomal proteins and microtubules. The generated ROS can also activate or repress the epigenetic mechanisms such as chromatin remodeling, non-coding RNAs (microRNAs), DNA (de) methylation and histone modification that affect gene expression, hence leading to various disease conditions like cancer, liver disease and many others [54]. It damages DNA leading to fanconi anaemia (FA) which is a chromosome-breakage disease that causes developmental defects, sterility, bone-marrow failure and a highly elevated risk of cancer and other body defects [27] (Figure 3).

It also forms adducts with central neurotransmitters in the brain such as dopamine that forms salsolinol, which may contribute to alcohol dependence, and with DNA to form carcinogenic DNA adducts such as $1, \mathrm{~N}^{2}$-propanodeoxyguanosine [21,24-26]. The formation of protein adducts in hepatocytes impairs protein secretion, which has been proposed to play a role in enlargement of the liver. Acetate, produced from the oxidation of acetaldehyde, is oxidized to carbon dioxide $\left(\mathrm{CO}_{2}\right)$ in heart, skeletal muscle and brain cells. Acetate can also affect various metabolic processes of the different organs and tissues such as depression of the central nervous system, and it can be metabolized to acetyl CoA, which is involved in lipid and cholesterol biosynthesis in the mitochondria of peripheral and brain tissues [21,24-26]. The generated ROS includes superoxide $\left(\mathrm{O}_{2}^{--}\right)$, hydrogen peroxide $\left(\mathrm{H}_{2} \mathrm{O}_{2}\right)$, hypochlorite ion $\left(\mathrm{OCl}^{-}\right)$and hydroxyl ( $\mathrm{OH})$ radicals, and the ROS acts by "stealing" hydrogen atoms from other molecules leading to the formation of the deleterious highly reactive free radicals that play an important role in the carcinogenesis, atherosclerosis, diabetes, inflammation, aging and other harmful processes to various organs and tissues in the body [21,24-26,28] (Figure 4).

The byproducts of ethanol metabolism such as acetaldehyde, acetate, reactive oxygen species (ROS) like hydroxyl radicals, superoxide anion and hydroxyl radicals and fatty acid ethyl esters (FAEEs) can disorganize the physiological body functions of various tissues, organs and especially the liver. Chronic use of alcohol overwhelms the liver and thus damages the liver cells, and together with the administered ARVs and the HIV virus, the damage is exacerbated, leading to massive release of liver enzymes into circulation and hence a rise in serum enzymes in the patients as a sign of liver toxicity. Also, the metabolic ethanol intermediate products like acetaldehyde and the generated free radicals can have deleterious effects to the body tissues and organs where they may interfere with the normal metabolism of essential elements, leading to cellular damage through oxidation mechanisms and secondary oxidative stress as well as the endocrine function disturbances [28-31]. Chronic alcohol consumption not only harms liver cells but also interferes with the normal functioning of the liver that later have an impact on the distant organs like the brain leading to hepatic encephalopathy [32]. However, excessive

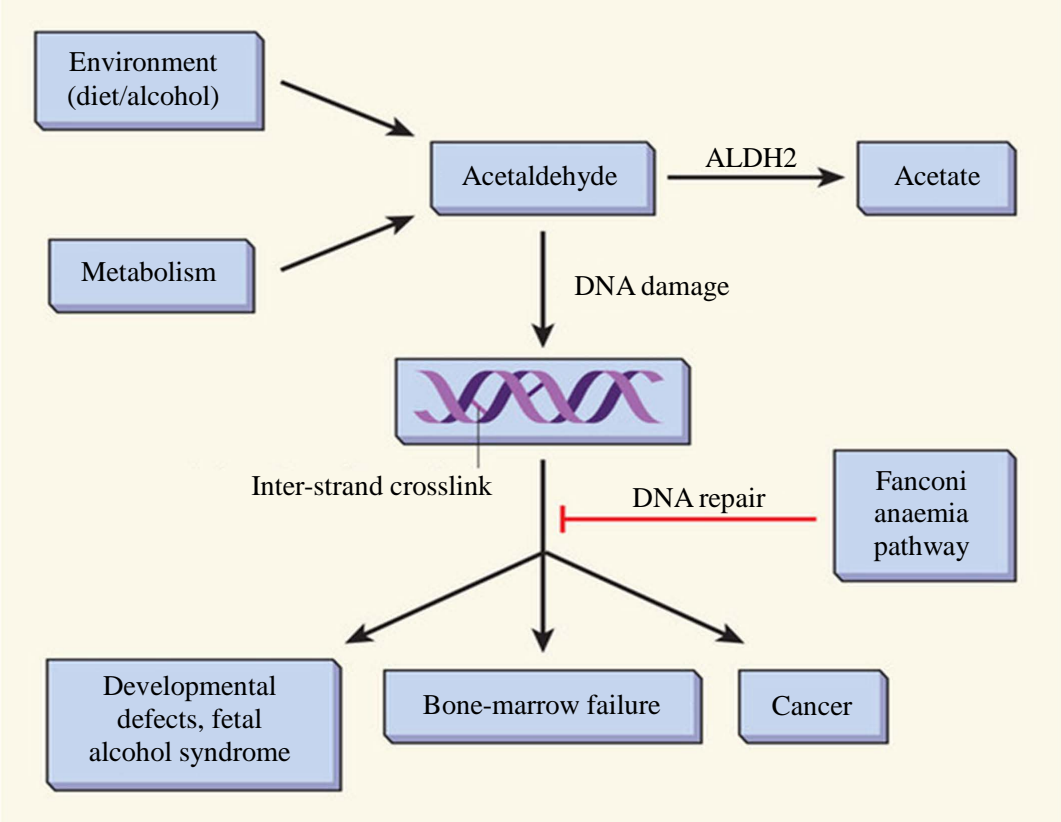

Figure 3. Acetaldehyde metabolism and the Fanconi anaemia pathway of DNA repair (Adopted from Joenje, 2011) [27]. 


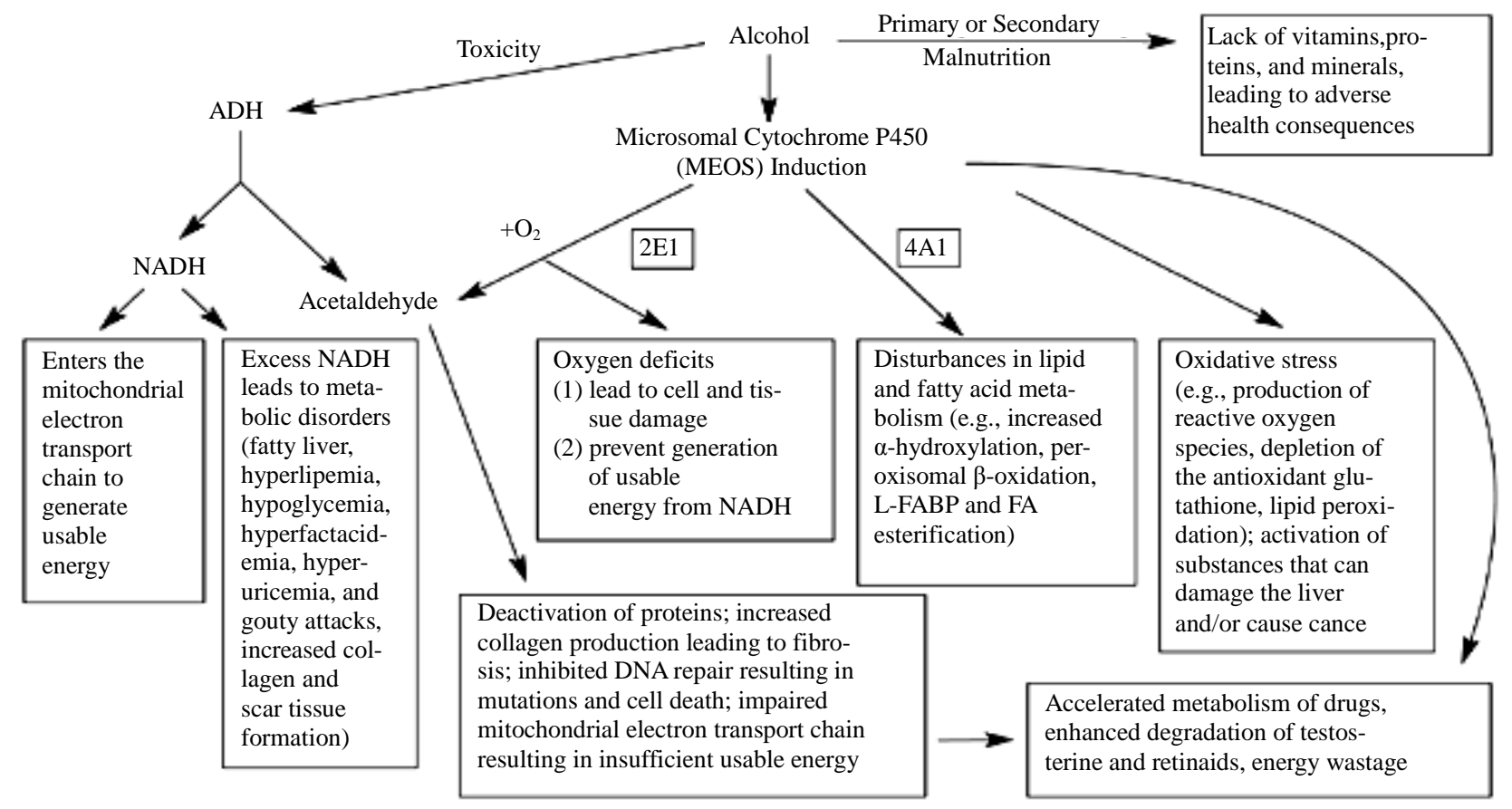

Figure 4. Effects of heavy alcohol consumption caused by alcohol-related malnutrition and alcohol breakdown by the enzyme alcohol dehydrogenase (ADH) and the microsomal ethanol-oxidizing system (MEOS); nicotinamide adenine dinucleotide (NADH), liver fatty acid binding protein (L-FABP), fatty acids (FA) (Adopted from Liber, 2004) [28].

consumption of alcohol leads to hepatocellular damage resulting in increased catalytic activities of serum AST and ALT [32-37]. Due to the high liver cell turnover, they are normally found in the blood. The ALT and AST are reported to be indicators of liver disease that may be due to alcohol induced liver damage. ALT is more specific to alcohol induced liver cell injury [33-37]. AST is also found in heart, muscle, kidney and brain cells [32-37]. Any injury or disease attributable to chemicals like drugs, aflatoxins and viral hepatitis [38,39], can increase the level of cellular injury or death to these organs, hence causing an elevation of the chronic alcohol use biomarkers [32-37]. The ratio of AST to ALT has been reported to provide more meaningful information on ethanol use especially if the ratio cut-off is greater than 2 [36,40-44]. The gamma glutamyl transferase (GGT) enzyme, a glycoprotein found in the liver, is the most widely used of all the liver enzymes to determine liver cell injury due to excessive alcohol consumption [36, 40-44]. The study therefore determined the effect of chronic alcohol use on the serum enzymes (alanine aminotransferase (ALT), aspartate aminotransferase (AST) and $\gamma$-glutamyl transferase (GGT) (AST/ALT) in the HIV-infected patients on d4T/3TC/NVP drug regimen using the chronic alcohol use self reporting WHO alcohol use disorders identification test (AUDIT) tool [45] and the chronic alcohol use biomarkers (ALT, AST,
GGT, AST/ALT $\geq 2.0$ and mean corpuscular volume (MCV)) methods [42,44] during the 9 month follow-up period.

\section{Materials and Methods}

\subsection{Study Design}

A case-control study that used repeated measures design with serial measurements was used to quantify the serum enzymes in the HIV infected patients who were exposed to chronic alcohol and at the same time, they were initiated on the $\mathrm{d} 4 \mathrm{~T} / 3 \mathrm{TC} / \mathrm{NVP}$ drug regimen [triomune 30 (lamivudine (3TC) $150 \mathrm{mg}$, nevirapine (NVP) $200 \mathrm{mg}$ and stavudine (d4T) $30 \mathrm{mg}$ tablets)] for the last 6 months. The $\mathrm{d} 4 \mathrm{~T} / 3 \mathrm{TC} / \mathrm{NVP}$ drug regimen was selected because during the time of the study, it was one of the first line drug regimens available for the treatment of HIV infected patients in the country. The serial measurements model was used to determine the serum enzymes at 3 month intervals (0, 3, 6 and 9 months) for a period of 9 month for both the control group and the chronic alcohol exposed group.

\subsection{Study Site and Population}

The study was conducted at St. Raphael of St Francis hospital, Nsambya ART clinic and at the Mulago National Referral Hospital Clinical Chemistry laboratory. 
The hospital handles about 1500 HIV-infected patients.

\subsection{Inclusion Criteria}

All the HIV-infected patients who were included in this study were HIV positive, on d4T/3TC/NVP drug combination regimen and were reported to have an adherence rate of above $95 \%$. Also those included were in the age range of 18 years to 50 years old. In the test group, they must be exposed to chronic alcohol use at that time and in the control group, they must have not been exposed to any type of alcohol at all or for the last 6 to 12 months.

\subsection{Exclusion Criteria}

All the patients who were exposed to other medications other than the $d 4 \mathrm{~T} / 3 \mathrm{TC} / \mathrm{NVP}$ and those reported to be using traditional herbs were excluded from the study. All the individuals with known liver and kidney problems were also excluded from the study. Individuals below 18 years of age were also excluded because they could not consent for themselves and the very young tend to have inefficient liver and kidney physiological functions. Also those above 55 years of age were excluded since they tend to start having liver and kidney problems. And those who refused to consent as well as obey the study guidelines were also excluded from the study.

\subsection{Eligibility Criteria and Enrolment of Study Participants}

The study was conducted on the HIV infected patients who were all initiated on the d4T/3TC/NVP drug regimen for the last 6 months. A total of 41 HIV infected patients on d4T/3TC/NVP were screened for chronic alcohol use using the WHO Alcohol Use Disorder Identification Test (AUDIT) tool. The 20 patients (13 males and 7 females) were identified to use ethanol chronically and the 21 patients (17 males and 4 females) were identified by the tool as non-alcohol consumers. The WHO AUDIT is a non-invasive method that is routinely used worldwide to screen patients exposed to chronic ethanol [45]. The AUDIT tool has a set of 10 questions, each with responses and scores which the individual responded to by self-reporting. A total score of 8 - 15 indicates hazardous alcohol use, 16 - 19 indicates alcohol use problem and scores above 20 indicates alcohol use dependence [45]. All the patients recruited in the chronic alcohol group had a total score of above 8 according to the WHO AUDIT tool interpretation of the scores. The patients enrolled in the control group had a score value of less than 8 (Box 1).
However because the WHO AUDIT was not sensitive enough to actually detect some of the patients in the control group who were consuming alcohol chronically, the chronic alcohol use biomarkers (GGT, MCV and AST/ ALT ratio) were used to further sort out the patients in the control group. The simultaneous elevation of GGT values above 55.0 UI, MCV values above $96 \mathrm{fL}$ and AST/ALT ratio above 2.0 were indicators of chronic alcohol use and these were monitored throughout the 9 months of study period, to ensure that there were no reverts and converts. The baseline serum enzyme concentrations (GGT, ALT and AST) at time 0 month just before they were initiated on the $\mathrm{d} 4 \mathrm{~T} / 3 \mathrm{TC} / \mathrm{NVP}$ drug regimen of all the patients that participated in the study were collected retrospectively from the patients records to ensure that these patients in the chronic alcohol use group were being exposed to alcohol. Therefore, the 41 HIV infected patients were again grouped according to the chronic alcohol use biomarkers into 2 groups. The chronic ethanol use group had 26 patients (22 males and 4 females) and the control group with 15 patients (8 males and 7 females). The patients in both the control and chronic alcohol exposed group were followed-up for 9 months starting from March 2008 to November 2008. All the patients who participated in the study signed the consent forms.

\subsection{Whole Blood Sample Collection and Processing}

About $3 \mathrm{ml}$ whole blood samples from the recruited HIV-infected patients were collected from cubital vein every 3 months for a period of 9 months (0, 3, 6 and 9th month) into the clot-activator vacutainers for serum extraction that was used for serum enzyme assays. The serum samples were extracted by centrifuging the clotactivator vacutainers with whole blood at 2000 revolutions per minute (rpm) for duration of 5 minutes. After which a clear supernatant of serum were transferred to the clean cryovials. The serum samples were immediately refrigerated at $-70^{\circ} \mathrm{C}$ prior to analysis. The liver function tests like the serum enzymes such as alanine amino transferase (ALT), aspartate amino transferase (AST) and the gamma-glutamyl transpeptidase (GGT) were used as biomarkers of chronic alcohol consumption. The liver function test study was carried out at the Mulago National Referral Hospital Clinical Chemistry laboratory with the use of the Cobas Intergra 400 Plus analyzer (Roche Diagnostics GmbH, Mannheim, Germany) using standard methods and laboratory standard operating procedures (SOPS). The results were entered into the excel spreadsheet and from there which they were analyzed statistically. 
Box 1. WHO alcohol use disorder identification test (AUDIT) tool with the 10 questions.

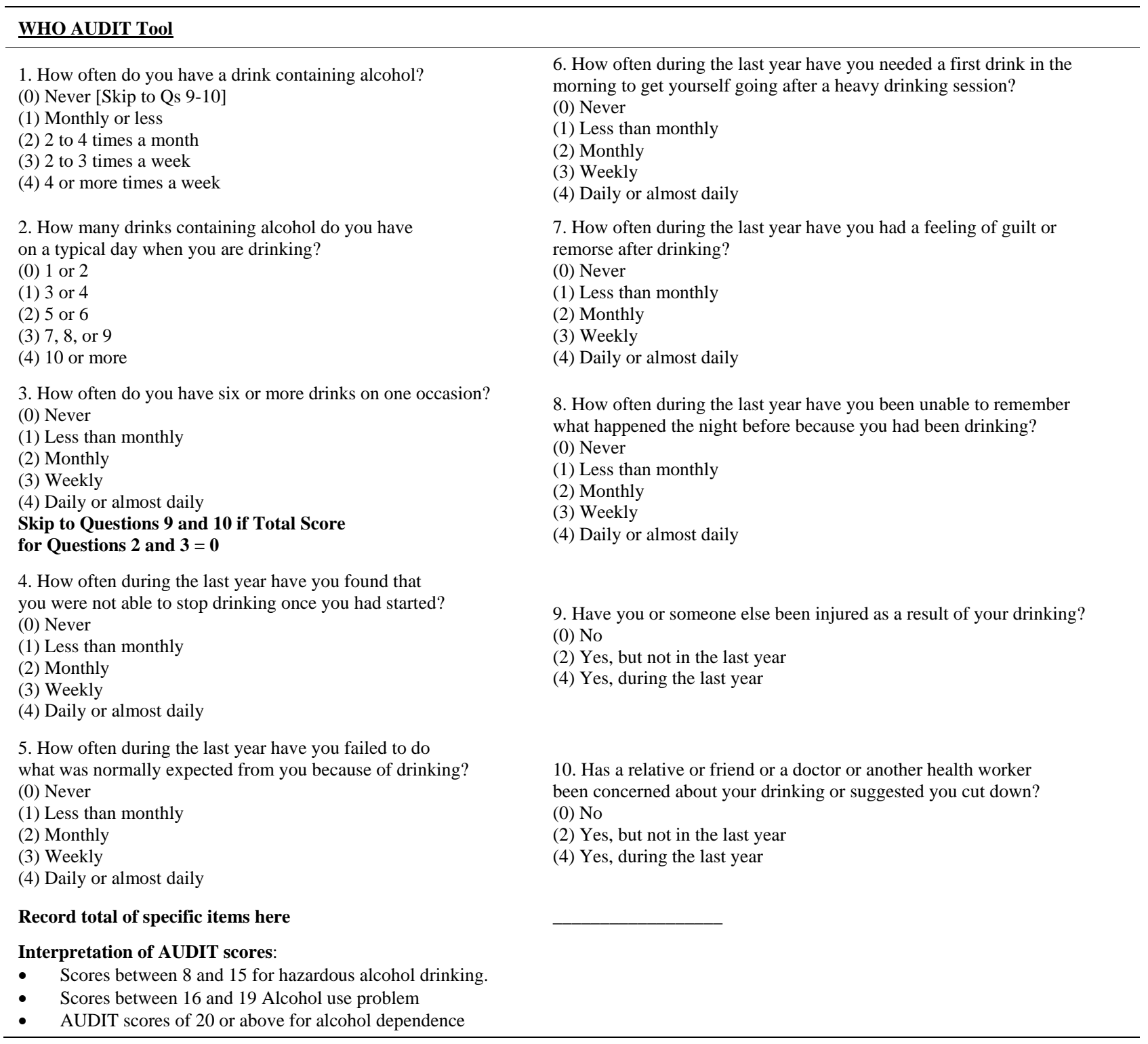

\subsection{Data Analysis}

The data was imported into the SAS 2003 version 9.1 statistical package for statistical data analysis. The data was analyzed at $95 \%$ confidence interval. The repeated measures fixed model was used in the statistical data analysis. The t-test was used to compare the means of serum enzymes for the chronic alcohol use (chronic alcohol use group) and the control group at different time intervals. The outcome measures were the mean difference of the measured parameters between the chronic alcohol use and non-alcohol use basing on the chronic alcohol use self-reporting WHO AUDIT tool method and the chronic alcohol use biomarkers. The $\mathrm{p}$ value of less than 0.05 was regarded as statistically significant.

\subsection{Ethical Consideration}

The research work was approved by the Faculty of Medicine Higher degrees, Research and Ethics committee of Makerere University Institution Review Board (IRB) (IRB\#-2007-060), IRB of St. Raphael of St Francis hospital, Nsambya (no. IRB 03: 01/03/2008) where the study participants were recruited from and the Uganda National Council for Science and Technology (UNCST) (no. HS 387), a government body that oversee all the research activities done in the country. In this study, a written informed consent was obtained from each participant and that all the procedures used were in accordance with the ethical standards of the responsible committee on human experimentation (institutional or regional) and with the 
Helsinki Declaration of 1975, as revised in 1983. They were given study code numbers which were used all through the study period in order to protect their privacy and confidentiality. Their names or any identifier were not used anywhere in the study.

\section{Results}

A total of 41 HIV-infected patients were recruited into the study. Twenty patients (13 males and 7 females) were identified to use ethanol chronically and the other 21 patients (17 males and 4 females) were identified by the WHO AUDIT tool as non-alcoholic consumers. And using the chronic alcohol use biomarkers, the chronic ethanol use group had 26 patients (22 males and 4 females) and the control group had 15 patients (8 males and 7 females). All the patients were in the age range of 18 - 55 years. The effect of chronic alcohol consumption on the liver (serum) enzymes (ALT, AST and GGT) levels were determined during the 9 months period of follow up for both the chronic alcohol use self reporting WHO AUDIT tool and the chronic alcohol use biomarkers methods. The mean GGT levels in the 6 and 9 month were higher than the reference ranges of $0-55 I U$ in both groups (Tables 3 and 4 ).

For the chronic alcohol use self reporting WHO AUDIT

Table 3. Variation of mean serum (liver) enzymes levels with time among the control and chronic alcohol use group.

\begin{tabular}{|c|c|c|c|c|c|c|}
\hline \multirow{2}{*}{\multicolumn{2}{|c|}{ Mean serum enzyme levels }} & \multicolumn{4}{|c|}{ Time of follow-up (months) } & \multirow{2}{*}{ Ref } \\
\hline & & $\mathbf{0}$ & 3 & 6 & 9 & \\
\hline \multicolumn{7}{|c|}{ Chronic alcohol use self reporting with WHO AUDIT tool } \\
\hline \multirow{2}{*}{$\mathrm{GGT} \pm \mathrm{SE}(\mathrm{Ul})$} & Control & $52.86 \pm 29.72$ & $53.87 \pm 28.70$ & $79.00 \pm 44.58$ & $104.08 \pm 70.84$ & \multirow{2}{*}{$0-55$} \\
\hline & Alcohol & $48.50 \pm 29.17$ & $49.40 \pm 28.20$ & $74.35 \pm 29.75$ & $148.17 \pm 105.89$ & \\
\hline $\mathrm{p}$ value & & 0.59 & 0.59 & 0.69 & 0.12 & \\
\hline \multirow{2}{*}{$\mathrm{AST} \pm \mathrm{SE}(\mathrm{Ul})$} & Control & $48.43 \pm 28.7$ & $38.57 \pm 25.00$ & $39.79 \pm 16.90$ & $42.29 \pm 55.43$ & \multirow{2}{*}{$0-46$} \\
\hline & Alcohol & $43.70 \pm 27.11$ & $44.75 \pm 23.65$ & $51.80 \pm 37.65$ & $28.54 \pm 8.19$ & \\
\hline $\mathrm{p}$ value & & 0.58 & 0.46 & 0.20 & 0.27 & \\
\hline $\mathrm{ALT} \pm \mathrm{SE}(\mathrm{Ul})$ & Control & $41.60 \pm 46.32$ & $23.90 \pm 15.33$ & $27.00 \pm 11.21$ & $33.81 \pm 22.75$ & $0-40$ \\
\hline p value & & 0.46 & 0.95 & 0.88 & 0.17 & \\
\hline \multirow{2}{*}{ AST/ALT } & Control & $1.65 \pm 1.23$ & $1.77 \pm 0.73$ & $1.61 \pm 0.64$ & $1.22 \pm 0.56$ & \multirow{2}{*}{$<2.00$} \\
\hline & Alcohol & $1.41 \pm 0.66$ & $2.00 \pm 0.66$ & $1.95 \pm 0.72$ & $1.19 \pm 0.43$ & \\
\hline \multicolumn{2}{|l|}{$\mathrm{p}$ value } & 0.55 & 0.25 & 0.03 & 0.86 & \\
\hline \multicolumn{7}{|c|}{ Chronic alcohol use biomarkers group } \\
\hline \multirow{2}{*}{$\mathrm{GGT} \pm \mathrm{SE}(\mathrm{Ul})$} & Control & $46.33 \pm 24.22$ & $44.00 \pm 27.82$ & $60.62 \pm 21.12$ & $68.04 \pm 36.37$ & \multirow{2}{*}{$0-55$} \\
\hline & Alcohol & $54.17 \pm 32.63$ & $55.04 \pm 32.97$ & $84.62 \pm 41.21$ & $155.17 \pm 97.39$ & \\
\hline p value & & 0.66 & 0.32 & 0.046 & 0.009 & \\
\hline $\mathrm{AST} \pm \mathrm{SE}(\mathrm{Ul})$ & Control & $41.34 \pm 20.57$ & $32.31 \pm 17.88$ & $32.77 \pm 9.22$ & $29.15 \pm 11.82$ & $0-46$ \\
\hline \multirow{2}{*}{$\mathrm{ALT} \pm \mathrm{SE}(\mathrm{Ul})$} & Control & $35.09 \pm 36.14$ & $22.13 \pm 12.22$ & $25.15 \pm 10.61$ & $28.82 \pm 18.29$ & \multirow{2}{*}{$0-40$} \\
\hline & Alcohol & $40.22 \pm 34.82$ & $25.64 \pm 16.55$ & $28.19 \pm 1.64$ & $31.06 \pm 18.66$ & \\
\hline $\mathrm{p}$ value & & 0.87 & 0.37 & 0.17 & 0.93 & \\
\hline \multirow{2}{*}{ AST/ALT } & Control & $1.47 \pm 0.53$ & $1.60 \pm 0.53$ & $1.45 \pm 0.57$ & $1.13 \pm 0.56$ & \multirow{2}{*}{$<2.0$} \\
\hline & Alcohol & $1.58 \pm 1.25$ & $2.06 \pm 0.69$ & $1.95 \pm 0.70$ & $1.24 \pm 0.56$ & \\
\hline p value & & 0.76 & 0.13 & 0.09 & 0.50 & \\
\hline
\end{tabular}

Key: Ref: Reference values; SE: standard error; GGT: gamma glutamyl transferase; AST: aspartate amino transferase; ALT: alanine aminotransferase. 
Table 4. Comparison of mean serum enzymes levels among the chronic alcohol use self reporting WHO AUDIT tool and chronic alcohol use biomarkers groups during the follow-up period.

\begin{tabular}{cccc}
\hline Mean serum enzyme & Control group & Chronic alcohol consumption & p value \\
\hline & Chronic alcohol use self reporting WHO AUDIT tool & 0.263 \\
GGT \pm SE (Ul) & $115.03 \pm 23.22$ & $151.39 \pm 21.81$ & 0.282 \\
AST \pm SE (Ul) & $44.45 \pm 10.50$ & $28.67 \pm 9.87$ & 0.208 \\
ALT \pm SE (Ul) & $35.37 \pm 4.77$ & $26.98 \pm 4.48$ & 0.029 \\
& Chronic alcohol use biomarkers group & 0.478 \\
GGT \pm SE (Ul) & $69.18 \pm 30.62$ & $153.09 \pm 19.36$ & 0.619 \\
AST \pm SE (Ul) & $28.03 \pm 15.29$ & $41.05 \pm 9.67$ & $30.62 \pm 3.84$ \\
ALT \pm SE (Ul) & $27.00 \pm 6.07$ &
\end{tabular}

Key: Ref: Reference values; SE: standard error; GGT: gamma glutamyl transferase; AST: aspartate amino transferase; ALT: alanine aminotransferase.

tool, the mean GGT levels in the control group were higher than in the chronic alcohol use group except in the 9 month and the difference in all were not statistically significant $(p \geq 0.05)$ (Table 3$)$. For the chronic alcohol-use biomarkers group, the mean GGT levels in 6 and 9 month for the control group and 0, 3, 6 and 9 month in the chronic alcohol use group were higher than the reference ranges (Table 3). The levels in the chronic alcohol use group were generally higher than in the control group and the difference was statistically significant $(\mathrm{p}=$ 0.046 and $\mathrm{p}=0.009$ ) in the 6 and 9 month respectively (Table 3). The overall mean GGT levels in chronic alcohol use group were higher than in the control group for both the chronic alcohol use self reporting WHO AUDIT tool and the chronic alcohol use biomarkers methods but the difference was statistically significant $(p=0.029)$ in chronic alcohol use biomarkers method and hence used as biomarker for chronic alcohol use (Table 4).

The mean AST levels were generally within the normal reference ranges of 0 - 46IU except in the 0 month for the control group and in the 6 month for the chronic alcohol use group (Table 3). For the chronic alcohol use self reporting WHO AUDIT tool, the levels were higher in the 0 and 9 month for the control group and in 3 and 6 month for the chronic alcohol use group but the difference was not statistically significant $(p \geq 0.05)$ (Table 3 ). For the chronic alcohol use biomarkers methods, the mean AST levels in the chronic alcohol use group were higher than the reference ranges in the 0,3 and 6 month follow up period (Table 3). Generally the mean AST levels in the chronic alcohol use group were higher than in the control group but the difference was not statistically significant $(\mathrm{p} \geq 0.05)$. The same effect was observed in the overall mean AST levels in both the chronic alcohol use self reporting WHO AUDIT tool and the chronic alcohol use biomarkers methods (Table 4).

For the ALT levels, the mean ALT values were within the normal reference ranges of 0 - 40IU except in the 0 month for the control group in the chronic alcohol use self reporting WHO AUDIT tool method and in 0 month for the chronic alcohol use group in the chronic alcohol use biomarkers methods (Table 3). The mean ALT levels in the chronic alcohol use group were higher than in the control group in the 3 and 6 month but the difference was not statistically significant $(p \geq 0.05)$ in the chronic alcohol use self reporting WHO AUDIT tool method (Table 3). For the chronic alcohol use biomarkers method, the mean ALT levels in the chronic alcohol use group were higher than in the control group in the 0, 3, 6 and 9 month period of follow up but the difference was not statistically significant ( $\mathrm{p} \geq 0.05$ ) (Table 3 ). The overall mean ALT levels in the control group were higher than in the chronic alcohol use group but the difference was not statistically significant $(p \geq 0.05)$ in the chronic alcohol use self reporting WHO AUDIT tool method. While for the chronic alcohol use biomarkers method, the overall mean ALT levels in the chronic alcohol use group were higher than in the control group, though still the difference was not statistically significant $(p \geq 0.05)$ (Table 4). For the mean AST/ALT ratio, the value was higher than 2.0 in the 3 month in the chronic alcohol use group for both the chronic alcohol use self reporting WHO AUDIT tool method and the chronic alcohol-use biomarkers method and hence used as a chronic alcohol consumption indicator when it exceed 2.0.

\section{Discussion}

The increased mean GGT levels in the HIV-infected patients on $\mathrm{d} 4 \mathrm{~T} / 3 \mathrm{TC} / \mathrm{NVP}$ drug regimen was due to chronic alcohol consumption and its metabolic ethanol intermediate products like acetaldehyde and free radicals generated during metabolism that can have a deleterious effects to the body tissues and organs especially the liver where they may interfere with the normal metabolism of essential elements, leading to cellular damage through oxidation mechanisms and secondary oxidative stress as 
well as the endocrine function disturbances [29-31]. Chronic alcohol consumption not only harm liver cells but also interfere with the normal functioning of the liver that later have an impact on the distant organs like the brain leading to hepatic encephalopathy [32]. The effects of the ingested ethanol on different organs depend on the ethanol concentration achieved in the tissue or organ and the duration of exposure. However, excessive consumption of alcohol leads to liver cell decay resulting in increased catalytic activities of serum AST and serum enzymes ALT. These enzymes metabolize amino acids. The ALT and AST are known to be indicators of liver disease in general and less specific to alcohol induced liver damage [33-37]. The increased byproducts of alcohol during the chronic alcohol consumption affect the liver cells by the increased destruction of the hepatocytes $[34,43,44]$. Also the slight increase in the mean GGT levels has been reported to be due to the prostate GGT, pancreas and kidneys $[34,43,44]$. It can also be due to the adverse effects of the drugs like stavudine (d4T) such as acute pancreatitis and hepatitis [46-50]; lamivudine (3TC) such as hepatomegally and lactic acidosis [46-50] and nevirapine such as hepatitis and hepatic failure [46-50]. The observed simultaneously increased levels of the mean AST and ALT indicate a sign of the liver cell decay or destruction leading to increased release of these liver enzymes in blood causing their increased catalytic activities. These enzymes metabolize amino acids and due to the high liver cell turnover, they are normally found in the blood circulation [34,44,51-53]. The raised ALT and AST are reported to be indicators of liver disease but less specific to alcohol induced liver damage. However, ALT has been reported to be more specific to alcohol induced liver cell injury than AST which can also be found in heart, muscle, kidney and brain cells. Any injury or disease that can increase the level of cellular injury or death in these organs can cause an elevation of these enzyme markers [34,44, 51-53]. The liver disease can be caused by a variety of agents including chemicals like alcohol and its metabolites [36], toxins like aflatoxins [39], drugs like the anticancer and antiviral drugs like the ARVs in this case stavudine [46,47,49,50], lamivudine $[46,47,49,50]$ and nevirapine $[46,47,49,50]$, injuries, anticancer and antiviral agents $[46,47,49,50]$ and infections like the viral hepatitis [38]. Chronic alcohol consumption leads to increased GGT, ALT and AST serum enzymes levels as well as the ratio of AST to ALT greater than $2.0[36,42,43]$ that has been reported to be associated with chronic ethanol use and the problems may be exacerbated by the HIV disease itself, the antiretroviral drugs used as well as the other concomitant medicines like the herbal preparations which the patients may be using during the 9 month follow up period.

\section{Significant Limitations of the Study}

1) It was difficult to quantify the daily alcohol consumption for the patients in their natural environment since this was an effectiveness type of study and therefore the WHO AUDIT tool and chronic alcohol use biomarkers are commonly used to screen patients for chronic alcohol use.

2) The use of the WHO AUDIT tool to screen the patients was not sensitive enough to detect some patients on chronic alcohol use and therefore chronic alcohol use biomarkers were used.

3) Since this was a follow up study, there was some loss to follow up of the patients during the 9 months period of follow up especially in the control group.

\section{Conclusion}

Chronic alcohol use by the HIV-infected patients on the $\mathrm{d} 4 \mathrm{~T} / 3 \mathrm{TC} / \mathrm{NVP}$ drug regimen affects the serum enzyme levels in blood circulation. The GGT enzyme levels were greatly raised in the chronic alcohol use group as compared to the control during the 9 months of follow-up. The serum/liver enzymes (GGT, AST and ALT) were monitored in this study as a way to determine the status of the liver since it was the main organ that metabolized many substances in the body such as drugs like the ARVS, chemicals like ethanol and other xenobiotics. The enzyme levels increased in circulation when the liver and other tissues and organs are damaged by the drugs, chemicals, chronic alcohol use, viral hepatitis infection and others. These enzymes are used as biomarkers of chronic alcohol use, and therefore they can be used in the therapeutic monitoring of the HIV-infected patient on chronic alcohol use as well as the adverse drug reactions associated with the ARVs. In this sub-study, chronic alcohol use greatly increased the GGT levels, and to some extent, the AST levels during the 9-month period of follow-up were higher in both the alcohol use self reported group and alcohol use biomarkers' group though the difference was more observed for the alcohol use biomarkers' group especially with the GGT levels.

\section{Acknowledgements}

I would like to acknowledge the following contributors to the success of this work Dr. Tugumisirize in the Dept of Pychiatry, Makerere University College of Health Sciences for the guidance and continued encouragement through the study period. I want to thank Sr. Justine Birungi, Sr. Plaxeda, Sr. Namugosa, Sr. Jesca and Dr. Kayima from the St. Raphael of St Francis hospital, Nsambya, Private clinic who assisted me a lot in the recruiting of the subjects and the collection of blood sam- 
ples from the patients. I want to thank the Director of St. Raphael of St Francis hospital, Nsambya and the Dr. Pius Okong, the chairman of IRB of the hospital for allowing me to conduct this study in the hospital. I also acknowledge the contribution of Dr. Norah Mwebaza and Mr. Dan Kibuule for all the support in this study.

\section{REFERENCES}

[1] D. B. Heath, "Anthropology and Alcohol Studies: Current Issues,” Annual Reviews Anthropology, Vol. 16, 1987, pp. 99-120.

http://dx.doi.org/10.1146/annurev.an.16.100187.000531

[2] G. Micheal, "Alcohol Health Issues Related to Alcohol Consumption,” The Place of Alcohol in Human Culture, 1996, pp. 1-22.

[3] Wikipedia, “Alcoholic Beverage,” Wikimedia Foundation Inc., St. Petersburg, 2009. http://en.wikipedia.org/wiki/Alcoholic_beverage

[4] WHO, "Global Status Report on Alcohol 2004," World Health Organization, Geneva, 2004.

[5] WHO, “Alcohol and Mental Health,” World Health Organization, Regional Office for Europe, WHO European Ministerial Conference on Mental Health, Helsinki, 12-15 January 2005; Helsinki Conference Secretariat, Copenhagen, 2005.

[6] WHO, "Alcohol and Injury in Emergency Department: Summary of the Report from the WHO Collaborative Study on Alcohol and Injuries," WHO Library Cataloguing-in-Publication Data, 2007, pp. 1-11.

[7] A. D. Johnson, "Female Alcohol Abuse Is a 'Global Epidemic',” New York Post, NYP Holdings, Inc., New York, 2013.

http://nypost.com/2013/10/05/female-alcohol-abuse-beco ming-global-epidemic/

[8] GENACIS, "Alcohol, Gender and Drinking Problems: Perspectives from Low and Middle Income Countries," World Health Organization, Geneva, 2005, pp. 2-241.

[9] J. Mbatia, R. Jenkins, N. Singleton and B. White, "Prevalence of Alcohol Consumption and Hazardous Drinking, Tobacco and Drug Use in Urban Tanzania, and Their Associated Risk Factors," International Journal of Environmental Research and Public Health, Vol. 6, No. 7, 2009, pp. 1992-2003. http://dx.doi.org/10.3390/ijerph6071991

[10] WHO-UNAIDS, "Global Adults and Children Estimated to Be Living with HIV in 2012 Report," World Health Organization, UNAIDS, 2012.

http://www.unaids.org/en/media/unaids/contentassets/doc uments/epidemiology/2013/gr2013/201309_epi_core_en. pdf

[11] UMoH, "Uganda AIDS Indicator Survey Report 2011," Uganda Ministry of Health (UMoH), 2011. http://blog.suubitrust.org.uk/2012/07/05/hiv-prevalence-i n-uganda-now-7-3/ http://ms-hiv-gdc.org/wp-content/uploads/group-documen ts/24/1334583717-UAIS-PRELIMINARYREPORT-MA

\section{RCH2012.pdf}

[12] A. Kafuko and P. Bukuluki, "Qualitative Research in Uganda on Knowledge, Attitude and Practices Concerning Alcohol, 2008," USAID, Health Communication, YEAH and Afford: Corporate Agreement Number 617-A00-07-00005-00, 2008.

[13] C. Lwanga-Ntale, "Drinking into Deeper Poverty: The New Frontier for Chronic Poverty in Uganda," Chronic Poverty Research Center, Development Research and Training, Policy Brief No.1/2007, 2007.

[14] I. S. Obot, "Alcohol Use and Related Problems in SubSaharan Africa,” African Journal of Drug and Alcohol Studies, Vol. 5, No. 1, 2006, pp. 17-25.

[15] YEAH, "Alcohol Consumption in Uganda: Literature Review,” Young Empowered and Health-YEAH, 2007. http://www.yeahuganda.org/research/AlcoholConsumptio $\underline{\text { n.pdf }}$

[16] B. Neild, "Uganda Leads Its African Neighbors for Alcohol Intake: World's 10 Best Drinking Nations," Cable News Network (CNN) Report, 2013.

http://edition.cnn.com/2013/03/15/travel/best-drinking-na $\underline{\text { tions/ }}$

[17] WHO, "Global Status Report on Alcohol and Health 2011,” World Health Organization Report, Geneva, 2011. http://www.who.int/substance_abuse/publications/global_ alcohol_report/msbgsruprofiles.pdf

[18] UNAIDS/WHO, "2007 AIDS Epidemic Update/Sub-Saharan Africa," Joint United Nations Programme on HIV/ AIDS (UNAIDS), World Health Organization (WHO) 2007, 2008, p. 11.

[19] WHO/UNICEF/UNAIDS, “Global HIV/AIDS Response: Epidemic Update and Health Sector Progress towards Universal Access, Progress Report 2011-2015,” World Health Organization HIV/AIDS Department, Geneva, 2011.

http://whqlibdoc.who.int/publications/2011/97892415029 86_eng.pdf

[20] C. I. Ehlers, "Variations in ADH and ALDH in Southwest Calfornia Indians," The Journal of the National Institute on Alcohol Abuse and Alcoholism, Vol. 30, No. 1, 2007, pp. 14-16.

[21] M. Y. Eng, S. E. Luczak and T. L. Wall, "ALDH2, ADH1B and ADH1C Genotypes in Asians: A Literature Review," The Journal of the National Institute on Alcohol Abuse and Alcoholism, Vol. 30, No. 1, 2007, pp. 22-26.

[22] D. M. Scott and R. E. Taylor, "Health-Related Effects of Genetic Variations of Alcohol-Metabolizing Enzymes in African Americans," The Journal of the National Institute on Alcohol Abuse and Alcoholism, Vol. 30, No. 1, 2007, pp. $18-20$.

[23] H. K. Seitz and P. Becker, "Alcohol Metabolism and Cancer Risk," The Journal of the National Institute on Alcohol Abuse and Alcoholism, Vol. 30, No. 1, 2007, pp. 38-46.

[24] S. Zakhari, "Overview: How Is Alcohol Metabolized by the Body?” The Journal of the National Institute on Alcohol Abuse and Alcoholism, Vol. 29, No. 4, 2006, pp. 245- 
252.

[25] M. W. King, "Ethanol Metabolism,” themedicalbiochemistrypage.org, 2013. http://themedicalbiochemistrypage.org/ethanol-metabolis $\underline{\text { m.php }}$

[26] K. S. Salmela, I. G. Kessova, I. B. Tsyrlov and C. S. Lieber, "Respective Roles of Human Cytochrome P-4502E1, 1A2 and 3A4 in the Hepatic Microsomal Ethanol Oxidizing System,” Alcoholism: Clinical and Experimental Research, Vol. 22, No. 9, 1998, pp. 2125-2132. http://dx.doi.org/10.1111/j.1530-0277.1998.tb05926.x

[27] H. Joenje, "Metabolism: Alcohol, DNA and Disease," Nature, Vol. 475, No. 7354, 2011, pp. 45-46. http://www.nature.com/nature/journal/v475/n7354/pdf/47 5045a.pdf http://dx.doi.org/10.1038/475045a

[28] C. S. Lieber, "Relationships between Nutrition, Alcohol Use, and Liver Disease," National Institute on Alcohol Abuse and Alcoholism (NIAAA), 2004. http://pubs.niaaa.nih.gov/publications/arh27-3/220-231.htm

[29] C. Berr, F. Clavel-Chapelon, S. Dally, J. Daval, F. Fumeron, C. Girre, et al., "Alcohol Health Effects," Inserm Centre of Collective Expertise, 2001, pp. 1-43.

[30] M. Gurr, "Alcohol Health Issues Related to Alcohol Consumption,” 2nd Edition, International Life Sciences Institute (ILSI) Europe, Washington DC, 1996, pp. 1-18.

[31] M. L. Ojeda, B. Vázquez, F. Nogales, M. Murillo and O. Carreras, "Ethanol Consumption by Wistar Rat Dams Affects Selenium Bioavailability and Antioxidant Balance in Their Progeny," International Journal of Environmental Research and Public Health, Vol. 6, No. 8, 2009, pp. 2139-2149. http://dx.doi.org/10.3390/ijerph6082139

[32] R. F. Butterworth, "Hepatic Encephalopathy: A Serious Complication of Alcoholic Liver Disease," Alcohol Research \& Health, Vol. 27, No. 2, 2003, pp. 143-145.

[33] M. Bilban, S. Vrhovec and M. Z. Karlovsek, "Blood Biomarkers of Alcohol Abuse," Archives of Industrial Hygiene and Toxicology, Vol. 54, 2003, pp. 253-259.

[34] S. Kubota, N. Amino, Y. Matsumoto, N. Ikeda, S. Morita, T. Kudo, H. Ohye, E. Nishihara, M. Ito, S. Fukata and A. Miyauchi, "Serial Changes in Liver Function Tests in Patients with Thyrotoxicosis Induced by Graves' Disease and Painless Thyroiditis,” Thyroid, Vol. 18, No. 3, 2008, pp. 283-287. http://dx.doi.org/10.1089/thy.2007.0189

[35] P. Mason, "Blood Tests Used to Investigate Liver, Thyroid or Kidney Function and Diseases,” The Pharmaceutical Journal, Vol. 272, 2004, pp. 446-448. www.pjonline.com

[36] B. R. Thapa and A. Walia, "Liver Function Tests and Their Interpretations,” Indian Journal of Pediatrics, Vol. 74, No. 7, 2007, pp. 663-671. http://dx.doi.org/10.1007/s12098-007-0118-7

[37] E. W. Tiemersma, P. A. Wark, M. C. Ocke, A. Bunschoten, M. H. Otten, F. J. Kok and E. Kampman, "Alcohol Consumption, Alcohol Dehydrogenase 3 Polymorphism, and Colorectal Adenomas," Cancer Epidemiology, Biomarkers \& Prevention, Vol. 12, No. 5, 2003, pp. 419-425.
[38] C. P. Wild and R. Montesano, “A Model of Interaction: Aflatoxins and Hepatitis Viruses in Liver Cancer Aetiology and Prevention," Cancer Letters, Vol. 286, No. 1, 2009, pp. 22-28. http://dx.doi.org/10.1016/j.canlet.2009.02.053

[39] J. W. Bennett and M. Klich, "Mycotoxins," Clinical Microbiology Reviews, Vol. 16, No. 3, 2003, pp. 497-516. http://dx.doi.org/10.1128/CMR.16.3.497-516.2003

[40] M. C. Braude and H. M. Chao, "Genetic and Biological Markers in Drug Abuse and Alcoholism,” National Institute on Drug Abuse (NIDA) Research Monograph 66 1986. Department of Health and Human Service. Alcohol, Drug Abuse, and Mental Health Administration. Maryland, 1996, pp. 1-50.

[41] K. M. Conigrave, L. J. Degenhardt, J. B. Whitfield, J. B. Saunders, A. Helander and B. Tabakoff, "CDT, GGT, and AST as Markers of Alcohol Use: The WHO/ISBRA Collaborative Project," Alcoholism: Clinical and Experimental Research, Vol. 26, No. 3, 2002, pp. 332-338. http://dx.doi.org/10.1111/j.1530-0277.2002.tb02542.x

[42] A. Helander, B. Tabakoff and WHO/ISBRA Study Centers, "Biochemical Markers of Alcohol Use and Abuse: Experience from the Pilot Study of the WHO/ISBRA Collaborative Project on State and Trait Markers of Alcohol," Alcohol \& Alcoholism, Vol. 32, No. 2, 1997, pp. 133-144.

http://dx.doi.org/10.1093/oxfordjournals.alcalc.a008247

[43] Y. Littner and C. F. Bearer, "Detection of Alcohol Consumption during Pregnancy-Current and Future Biomarkers," Elsevier publishers, Neuroscience and Biobehavioral Reviews, Vol. 31, No. 2, 2007, pp. 261-269.

[44] SAMHSA, "The Role of Biomarkers in the Treatment of Alcohol Use Disorders," US Center for substance Abuse Treatment Substance Abuse and Mental Health Service Administration, 2006.

[45] T. F. Babor, J. C. Higgins-Biddle, J. B. Saunders and M. G. Monteiro, "The Alcohol Use Disorders Identification Test (AUDIT) Manual: Guidelines for Use in Primary Care,” 2nd Edition, Department of Mental Health and Substance Dependence, World Health Organization, 2001, pp. 4-32.

[46] J. G. Bartlett and J. E. Gallant, "Medical Management of HIV Infection,” Johns Hopkins University School of Medicine, Johns Hopkins Medicine Health Publishing Business Group, Baltimore, 2006.

[47] L. L. Brunton, J. S. Lazo and K. L. Parker, "Antiretroviral Agents and Treatment of HIV Infection,” Goodman and Gilman's the Pharmacological Basis of Therapeutics, 11th Edition, McGraw-Hill, New York, 2006, pp. 12731309.

[48] G. Gómez-Moreno, J. Guardia, A. Cutando and J. CalvoGuirado, "Pharmacological Interactions of Anti-Microbial Agents in Odontology,” Medicina Oral, Patología Oral y Cirugía Bucal, Vol. 14, No. 3, 2009, pp. E123-E128.

[49] R. M. W. Hoetelmans, "Clinical Pharmacokinetics of Antiretroviral Drugs,” AIDS Reviews, Vol. 1, No. 3, 1999, pp. 167-178.

[50] C. Hoffmann, J. K. Rockstroh and B. S. Kamps, "HIV 
Medicine 2007,” 15th Edition, Flying Publisher, 2007, Vol. 1, pp. 23-29. www.HIVMedicine.com

[51] C. F. Bearer, J. M. Stoler, J. D. Cook and S. J. Carpenter, "Biomarkers of Alcohol Use in Pregnancy," Alcohol Research \& Health, Vol. 28, No. 1, 2005, pp. 38-42.

[52] S. K. Das, P. Nayak and D. M. Vasudevan, "Biochemical Markers for Alcohol Consumption,” Indian Journal of Clinical Biochemistry, Vol. 18, No. 2, 2003, pp. 111-118. http://dx.doi.org/10.1007/BF02867376
[53] T. P. Dergisi, "The Diagnostic Validity of Screening Tests and Laboratory Markers in Alcohol Use Disorders," Turkish Journal of Psychiatry, Vol. 16, No. 1, 2005, pp. 312.

[54] J. J. Day and J. D. Sweatt, "Review of Epigenetic Mechanisms in Cognition,” Neuron, Vol. 70, No. 5, 2011, pp. 813-829. http://dx.doi.org/10.1016/j.neuron.2011.05.019 